\title{
Development Status of Electronic Commerce and Exploration of Coping Strategy: from the Viewpoint of IE4.0
}

\author{
Chien-Hua Shen ${ }^{1}$, Chun-Mei Chou ${ }^{2 *}$, Nguyen Thi Ngoc Lien \\ ${ }^{3}$, Jia- Ming Chen ${ }^{4}$, Kuan-Fu Shen ${ }^{5}$, Hsiang-Li Shen ${ }^{6}$ \\ ${ }^{1}$ Department of Business Administration, Transworld Institute of Technology, Yunlin , Taiwan \\ E-mail: shen17@ms51.hinet.net \\ $2^{\star}$ Institute of Vocational and Technological Education, National Yunlin University of Science \& \\ Technology, Yunlin, Taiwan \\ E-mail: choucm@yuntech.edu.tw \\ ${ }^{3}$ Department of Business Administration, TransWorld University, Yunlin , Taiwan/ China. \\ E-mail: yulian.ruan@gmail.com \\ ${ }^{4}$ Institute of Vocational and Technological Education, National Yunlin University of Science \& \\ Technology, Yunlin, Taiwan \\ ${ }^{5}$ Chien Hsin University of Science and Technology Department of Finance, Taoyuan, Taiwan \\ ${ }^{6}$ Chien Hsin University of Science and Technology Secretariat Office, Taoyuan, Taiwan
}

Keywords: Industry 4.0; Electronic commerce; Vietnams

\begin{abstract}
Industry 4.0 has been proposed and adopted by the German government as part of the “High-Tech Strategy 2020 Action Plan”. The Industry 4.0 describes a CPS oriented production system that integrates production facilities, warehousing systems, logistics, and even social requirements to establish the global value creation networks . This research aims to explore the situation and problems of Vietnam's Electronic Commerce (EC), and provides suggestions as reference for the relevant units of enterprises and government. In order to achieve this goal, this research adopts the literature analysis method to explore the status and problems in Vietnam's electronic commerce, including enterprises, customers, and the integral dimension, and provides a coping strategy as reference.
\end{abstract}

\section{Introduction}

The vertical integration of various components inside a factory to implement a flexible and reconfigurable manufacturing system, i.e., smart factory, is one of the key features of Industry 4.0. The digital transformation changes business and private life likewise - in a radically and sustainable way. The economic potential is enormous. Topics related to the networking of the internet by far have the most economical potential worldwide. The world becomes more and more digital. This is the Big Business of the future in Taiwan [3] [4].

Vietnam EC (Electronic Commerce) has developed rapidly in recent years, and 2015 was the golden year for Vietnam EC development. The development of EC in Vietnam has faced the problems of trust crisis and lack of talents, thus, how to avoid crisis and create favorable conditions for EC development in the future has become the primary topic. Therefore, this research discusses 
the present situation and problems of Vietnam's EC development through literature analysis in order to put forward suggestions and provide reference for relevant units.

\section{Vietnam EC Development Status}

\section{Vietnam EC develops year by year}

According to the data of Vietnam's EC Development Council in 2014 [1], the output value of Vietnam's B2C electronic commerce is 2.97 billion USD, accounting for $2.12 \%$ of Vietnam's retail market, and each consumer purchases an average of 145 USD. It is estimated that B2C and the EC market of Vietnam will reach 10 billion USD by 2020, meaning a growth of 25\%. According to the 2015 statistical data of VECITA (Vietnam E-Commerce and Information Technology Authority) [2], Vietnam's EC market grew from 700 million USD in 2012 to 4.07 billion USD in 2015 (about 160 USD of average online shopping for each person); however, the total value of products sold through network retail channels only accounts for $2.8 \%$ of the total income of retail sales. The types of products with the largest online sales are clothes, shoes, and cosmetics (64\%), followed by electronic products, household items, books, and office supplies. The electronic commerce with the top 10 sales incomes include: Lazada, Chodientu, HotDeal, Rongbay, Vatgia, Enbac, Adayroi, Sendo, Cungmua, and Deca.

\section{Smartphones motivate the development of EC}

According to the 2014 consumer behavior survey results of Google Inc. and the market consulting company of Taylor, Nelson, and Sofres, 36\% of Vietnamese have a smartphone, and this number was only $20 \%$ in 2013 . As smartphones become increasingly popular, retailers can easily contact consumers and promote the rapid development of the retail industry. It is estimated that one third of the 30 EC companies in Vietnam have developed telephone Apps for users when online shopping through a smartphone or tablet computer. These EC companies include Lazada, Zalora, VatGia, CungMua, NhomMua, and Hot Deal [3].

\section{Rejuvenation of population hastens the development of EC}

Vietnam's network has high popularity, as the young population accounts for a large proportion (population under 35 years old accounts for $61 \%$, while the population under 30 years old accounts for 56\%). The number of people online in Vietnam is the largest in Southeast Asia. In 2015, there were 41 million online consumers (accounts for about $42 \%$ of the total population), of which $42 \%$ of online users are people aged between 15 to 24; Vietnamese spend an average of 26 hours and 12 minutes per month surfing the Internet, and half of those people are engaged in online shopping. The most popular online shopping products for young people include clothes and cosmetics (62\%), electronic products (35\%), home supplies (32\%), and flight tickets (25\%) [4] [5] [6].

\section{Problems in EC Development in Vietnam}

Although Vietnam's EC market has rapid development, there exist the following problems:

\section{Network financial trade is not mature}

Many online shoppers have no credit card in Vietnam, thus, pay on delivery is the main trade mode in the EC market, payment through an electronic wallet accounts for 8\%, and payment through a mobile phone card or game card accounts for $7 \%$. According to the survey results, 59\% of consumers say that it is difficult to find good quality products on the network; $41 \%$ claim that online retailers are not trustworthy; 38\% think that online product information is not comprehensive, and $37 \%$ state that they do not use credit cards [7] [8].

\section{Current EC market in Vietnam is a mess}

In a word, the root of Vietnam's current economic problems is the country's style of gradualism. In the earlier stages of Doi Moi, the gradualism of Vietnam's transition strategy was effective because reforms focused on agriculture and FDI, and the existence of SOEs was not an obstacle in resource allocation. But SOEs have now become state conglomerates, affecting Vietnam's economic policies and factor markets. [9] 
Most small and medium-sized Vietnamese enterprises lack the talents to apply, exchange, develop, and construct EC technology. In addition to relevant laws adverse to the development of EC, mediation modes for commercial trade disputes have not yet been formed [10].

\section{Conclusion and Suggestions}

Vietnam's EC market has very large space for development, which attracts the investment of more foreign network retailers. In the process of vigorous development, common people have insufficient confidence in online shopping, trade disputes are difficult to resolve, and problems in the payments of online shopping hinders the development of EC. This research offers the following suggestions regarding the abovementioned problems:

\section{In terms of relevant government departments}

(1) Handle EC related research and promotion activities: the government should promote training plans to further encourage Taiwanese companies to widely use all kinds of EC forms, such as B2C, B2B, and B2G; establish and promote a Vietnamese EC development index, offer national EC development awards, train EC human resources, and set up network shopping operation solutions for the development of small and medium-sized enterprises.

(2) Push and open third party payment service: third party payment services have become a popular payment mode in international EC. Unless foreign online shopping platforms are used in Vietnam, only credit card or bank transfer payments are provided. Therefore, payment options are required in order to promote the development of the EC industry and fully guarantee the rights and interests of consumers.

(3) Strengthen network infrastructure: the future consumption trend is the implementation of online shopping through smart phones, tablet computers, and other mobile devices, thus, the government should help to improve the network infrastructure, which would be helpful to the development of a new EC mode in the future.

\section{In terms of enterprises}

(1) Build consumer trust: EC enterprises should strictly control product quality, cultivate good service attitude, establish good brand image, improve trust in the online mode, eliminate the doubts of consumers regarding online shopping, and increase the confidence of consumers towards the brand.

(2) Complete mobile information device: the ability of EC enterprises to complete sales channels through a mobile terminal is mature, thus, retailers must strengthen their website functions and information devices in order to achieve an impregnable position in future competition.

(3) Promote international cooperation: Vietnam's EC enterprises should establish cooperative relations with foreign enterprises in order to promote close cooperation of business, and they should be committed to using the advantages of both parties in order to strengthen the competitiveness of the enterprise itself.

\section{Acknowledgment}

This paper was written while the authors were supported by a grant from the National Science Council, R.O.C. (MOST 105-2511-S-224-001-MY3) 


\section{References}

[1] Latest Market Situation of Vietnam E-commerce: 2014 Transaction Value is nearly 3 billion USD, increasing greatly by $36 \%, \quad 2015 . \quad$ Retrieved from:http://www.bnext.com.tw/article/view/id/36725

[2] Total Business Turnover of 4 Billion USD of Vietnam E-commerce in 2015, 2016. Retrieved from: http://www.mofcom.gov.cn/article/i/jyjl/j/201604/20160401304207.shtml

[3] Development Status of Vietnam EC Market, 2014. Retrieved from http://sv.taiwantrade.com.tw/org2/1/news_detail/zh_TW/83047/I

[4] K. Schuster, K. Groß, R. Vossen, A. Richert, and S. Jeschke, "Preparing for Industry 4.0collaborative virtual learning environments in engineering education," The International Conference on E-Learning in the Workplace (ICELW 2015) June 10 th -12 th , New York, NY, USA. (2015).

[5] S. Wang, J. Wan, D. Li, and C. Zhang. "Implementing Smart Factory of Industrie 4.0: An Outlook,’International Journal of Distributed Sen- sor Networks, in press(2016).

[6] E.M. Frazzon , J. Hartmann , T. Makuschewitz , B. Scholz-Reiter. “ To- wards socio-cyberphysical systems in production networks.” Proce- dia CIRP (7) (2013): 49-54 .

[7] Wang, S. Wan, J., Zhang, D., Li, D., and Zhang, C. “Towards smart factory for industry 4.0: a self-organized multi-agent system with big data based feedback and coordination.” Computer Networks 101(4) (2016): 158-168.

[8] Lee, J., Bagheri, B., and Kao, H.A. "Research Letters A Cyber-Physical Systems architecture for Industry 4.0-based manufacturing systems “. Manufacturing Letters 3 (2015): 18-23.

[9] Faller, C., and Feldmüller, D. “Industry 4.0 Learning Factory for regional SMEs.” Procedia CIRP 32(2015): 88 - 91.

[10]Schuh, G., Gartzen, T., Rodenhauser, T. and Marks, A. "Pormoting work-based learning through Industry 4.0.” Procediia CIRP 32 (2015): 82-87. 